The BMJ

Cite this as: BMJ 2020;371:m4615 http://dx.doi.org/10.1136/bmi.m4615 Published: 30 November 2020

\section{How can I ask a colleague to work my Christmas shift?}

\author{
It can be difficult to know how to approach asking for a shift swap over the holiday period. Abi \\ Rimmer gets advice from experts.
}

Abi Rimmer

\section{"I don't need a sob story"}

Simon Fleming, orthopaedic registrar, says, "This feels like a confession, even though it shouldn't: I'm a grinch.

“I just don't enjoy Christmas at all. Although I like the idea of time with family and of thoughtful gifts, and, let me be really clear here, I love the food (except turkey, which is awful), I'm aware that Christmas is for many a time that has layers of nostalgia and emotion. Childhood memories, happy and bittersweet alike. I, however, never did Christmas at home; for me it was just a time when all my friends were busy and TV was a bit repetitive.

“Christmas makes people reflect on those they've lost, and for those with children or elderly relatives there are additional pressures I cannot begin to understand. So, I write this from two perspectives-as someone who is more than happy to work Christmas for you but also someone who has a partner who loves Christmas and might murder me if I do.

"What I would say is this: I don't need the TV talent show sob story and I don't need to be made to feel guilty or asked where my Christmas spirit is. These things don't work on me. I have no Christmas spirit, never have. Instead, if I am free, just ask me. Just like any other swap. Offer to do New Year's Day for me or another shift that suits.

"I promise, if I can help you and you ask with respect, chances are I will say yes. My partner will understand and one day, when I'm the one asking, I hope the person I ask feels the same way."

\section{"Be willing to compromise"}

Zirva Khan, salaried GP in North Staffordshire, says, “This isn't a difficult task, but very easy to get wrong.

"Some departments that I've worked for have been quite good and have an 'opt-in' system where people will volunteer to work over the holiday period. I worked most Christmas shifts when in hospital rotations, often voluntarily swapping into them. I don't celebrate Christmas but valued those who would cover shifts of mine I wanted off, including Eid days.

“Firstly, don't make assumptions about who doesn't celebrate Christmas. Many who you think don't celebrate it, do, and vice versa.

"Secondly, plan in advance. Send emails to your colleagues, approach people politely, and feel free to be open about why you need the shift covered. As silly as this sounds, we are empathetic people and do care about each other. A swap for a day they really need off is usually the expectation.
"Thirdly, be willing to compromise. You may get an offer to get the day off but work the night, or work the morning and have afternoon or evening off. Pick the most suitable option, don't push. If you are unlucky enough to be allocated shifts on both Christmas and New Year, you may not get swaps for both. Therefore, choose wisely.

"Lastly, if you do end up working at Christmas, it's one of the best on-call shifts you'll work. There'll always be a sad story, but I've never seen the staff and patients so happy."

\section{"Plan ahead"}

Umair Gondal, GP trainee, says, “There are a few aspects to consider when asking a colleague to cover your shift for Christmas.

"Firstly, everyone deserves time off and that's why a fair rota has been designed to cover the Christmas period, usually with just the essential staffing levels. Being mindful of your needs compared with others is important. For some people it may be their last Christmas with a loved one. Other people might not live close to their family and this might be the only chance they get to spend quality time with them.

"Secondly, think about what you're able to offer in return if there's someone available to cover your shift. Personally, I've always been open to swapping shifts for colleagues who would like Christmas off. This favour is usually repaid. The fairest way would be to arrange to cover an equivalent shift that the person you are asking would like to take off, for example for their birthday or a wedding. My fiancée and I planned our engagement far in advance, allowing time to organise a shift swap. I covered a colleague's Christmas shift and in return they covered my on-call shift around my engagement day.

"Given the popularity of the Christmas period, arranging swaps with two to three months' notice is easier than asking someone the week before. Christmas occurs every year at the same time-there's no excuse for not planning ahead. Contacting your rota coordinator may help to identify colleagues who aren't working on Christmas Day.

“Overall, planning early, identifying and contacting key people, and offering flexibility in return will help to increase your chances of arranging time off over Christmas."

\section{"Be prepared to offer something in return"}

Salman Waqar, GP and academic research fellow at the Nuffield Department of Primary Care Health Sciences, University of Oxford, says, "Christmas Day is generally a pleasant day to work. For the most part, 
staff are suitably attired in jumpers, tinsel glitters in the halls, patients are desperate to stay at home, and the roads are quiet. Boxing Day is another story, but let's ignore that.

“For doctors like me who don't celebrate Christmas-but who'll happily indulge in festive TV-it's not much of an ask to cover a colleague's shift. We just need plenty of notice-I'm talking the first week of August-so that we don't end up getting roped into plans that we can't get out of.

"I’ve found it works well to ask for festive swapsies: 'If you cover my Christmas, I'll do your Eid, Diwali, Rosh Hashana,' works nicely. This can be a challenge for rotating junior doctors during short placements and those in small teams where someone is likely to come up short and be unable to repay the favour. The Christmas swap is a popular one, so be prepared to offer a bank holiday night shift in return to ward off the competition.

"Failing that, try and see if you can do a half day each, so at least you can have a Christmas brunch or dinner-even if it's with reluctant flatmates and not family living far away. Ask your rota coordinator if you can tweak the timings so that it works for you." 